\title{
Elevation of Plasma Lathosterol, as an Indicator of Increased Cholesterol Synthesis, in Preterm (23-32 Weeks Gestation) Infants Given Intralipid
}

\author{
J. J. HAMILTON, M. PHANG, AND S. M. INNIS
}

Department of Pathology [J.J.H.] and Department of Pediatrics [M.P., S.M.I.], University of British Columbia, and British Columbia Children's Hospital, Vancouver, British Columbia, Canada V5Z 4 H4

\begin{abstract}
Hypercholesterolemia is common in preterm infants administered $10 \%$ Intralipid perhaps because of excess phospholipid in plasma causing efflux of cholesterol from tissues. The purpose of this study was to determine if cholesterol synthesis (as measured by plasma lathosterol) is increased in preterm infants (23-32 wk gestation) during infusion of up to $4 \mathrm{~g} \mathrm{10 \%}$ Intralipid/ $/ \mathrm{kg}$ body wt/d. Two groups of infants were studied. Intralipid intake was compared to: 1) plasma cholesterol in blood sampled over the first $100 \mathrm{~d}$ of life (preliminary study, $n=22$ ) and 2) plasma cholesterol, lathosterol, and apo $\mathrm{AI}$ and $\mathrm{B}$ in blood taken at birth (cord), d 3-4 of life, and at least three additional times over the next $25 \mathrm{~d}$ (lathosterol study, $n=$ 22). Lathosterol was quantitated by gas liquid chromatography and apo $A I$ and $B$ by immunoprecipitation. In the preliminary study, plasma cholesterol levels rose (to 4.06$10.70 \mathrm{mM}$ ) with Intralipid administration. Infants who received $<2 \mathrm{~g}$ Intralipid/ $\mathrm{kg}$ body wt/d were not hypercholesterolemic. In the lathosterol study, plasma cholesterol increased (1.86-2.24 mM, $p=0.06)$ and apo AI and B did not change, but lathosterol and the cholesterol:lathosterol ratio decreased (5.24-2.88 $\mu \mathrm{M}, p=0.01$, and 284-124 10 $x$ mmol lathosterol:mol cholesterol, $p=0.007$, respectively) from birth to $\mathrm{d} 3-4$ ( $n=11$ paired samples). Infants followed longitudinally had increased cholesterol and lathosterol (4- to 7-fold) with increasing Intralipid administration, which decreased after discontinuation of infusion. Apo AI and B decreased upon Intralipid infusion. The results of this study show that $10 \%$ Intralipid administration to preterm infants (23-32 wk gestation) results in increased plasma lathosterol. The coincident fall in plasma apo AI and B suggests that the elevated cholesterol synthesis may be extrahepatic. (Pediatr Res 31: 186-192, 1992)
\end{abstract}

Abbreviations

HMG CoA, 3-hydroxy-3-methylglutaryl coenzyme A apo, apolipoprotein

An increase in plasma cholesterol levels in the 1st wk of life is normal in term infants (1). Postnatal changes in preterm infants

Received June 5, 1991; accepted September 20, 1991.

Correspondence and reprint requests: S. M. Innis, Ph.D., Department of Pediatrics, University of British Columbia, Rm 179, Research Centre, 950 W. 28th Ave., Vancouver, B.C., Canada V5Z 4H4.

Supported by a grant from the British Columbia Medical Services Foundation. J. J. H. is the recipient of a British Columbia Children's Hospital Research Division Studentship. S. M. I. is supported as a Career Investigator of the British Columbia Children's Hospital. are less clear, but there have been many reports of hypercholesterolemia (2-13) beyond the levels observed either in utero (14) or in healthy term infants (1). This is attributed to i.v. lipid administration and has also been noted in similarly treated term infants $(2,4,5,15)$ and adults $(16,17)$. Griffin et al. (2) showed that infusion of $10 \%$ Intralipid (KabiVitrum Canada Ltd., Newmarket, Ontario, Canada), resulted in elevated plasma cholesterol in neonates, and estimated $50 \%$ of the increase was from endogenous sources. Increased efflux of nonesterified cholesterol from tissues to plasma, with accumulation of cholesterol in a lipoprotein known as LpX (2), might result in enhanced cholesterol synthesis to replace membrane cholesterol lost to the plasma. To the best of our knowledge, cholesterol synthesis has not been measured in preterm infants during i.v. lipid feeding.

Cholesterol synthesis is commonly determined by assay of the activity of liver HMG COA reductase (EC 1.1.1.34) (18), plasma mevalonate (19), or deuterated water incorporation into cholesterol (20). Although not involving liver biopsy, the latter two methods require laborious methodology or blood volumes too large for infant studies. Cholesterol synthesis has also been measured in vivo by quantitation of plasma lathosterol, a sterol precursor of cholesterol, by gas-liquid chromatography (21). Plasma concentrations of lathosterol are correlated with the rate of hepatic HMG CoA reductase activity in adult humans (22).

The primary objective of this study was to determine lathosterol levels in preterm infants preceding and during $10 \%$ Intralipid administration. Subjects ranged from 23-32 wk gestation, inasmuch as these infants most often require parenteral nutrition with Intralipid. Plasma apo AI and B and nonesterified and total cholesterol concentrations were measured as indicators of HDL, $\mathrm{LDL}$, and $\mathrm{LpX}$. First, a preliminary study was conducted to document the association between plasma cholesterol levels and Intralipid administration at this facility.

\section{MATERIALS AND METHODS}

Preliminary Cholesterol Study. Infants. All infants of 24-32 wk gestation admitted between April and August 1989 to the Special Care Nursery of the British Columbia Children's Hospital in Vancouver were followed. Results are given for the 21 infants, with birth weight appropriate for gestational age, for whom at least five plasma samples were obtained (the first within $2 \mathrm{wk}$ of birth). Medical care was given at the discretion of the attending physicians with no regard to this study. Generally, infants were nourished via a peripheral vein immediately after birth with glucose (D5W or D10W; Baxter Corp., Toronto, Ontario, Canada), followed by the inclusion of amino acids (Vamin A or B; KabiVitrum Canada Ltd., Newmarket, Ontario, Canada) and Intralipid (0.5-4 g/ $\mathrm{kg}$ body wt/d) over the next week. Lipids were mixed with $2 \mathrm{IU}$ heparin $/ \mathrm{mL}$ and infused at a constant, continuous rate. Expressed breast milk and/or formula (Similac Special Care or Pregestimil, Ross Laboratories, Columbus, $\mathrm{OH}$ 
or Enfalac or Prosoybee, Mead Johnson, Belleville, Ontario, Canada) were fed by nasogastric bolus as tolerated. Gestational age, birth weight, sex, daily weight gain, and enteral and parenteral feeding data were recorded.

Samples. Blood was collected by heel prick into capillary tubes for hematocrit analysis as part of the medical care, the tubes were spun and results were read within $2 \mathrm{~h}$ of sampling, and plasma was recovered from the tube. Additional samples were acquired when excess plasma remained from other required laboratory tests. Plasma was stored at $-70^{\circ} \mathrm{C}$. Samples were analyzed for total cholesterol as described below.

Lathosterol Study. Infants. The 22 infants followed in this study were born at 23-32 wk gestation at Grace Hospital and admitted to the Special Care Nursery of the British Columbia Children's Hospital between February and August 1990. A requirement of a concurrent study was that infants be intubated from birth. Infants' medical and dietary history was collected as above. Serum bilirubin and history of prenatal maternal dexamethasone treatment were recorded.

Samples. The umbilical cord was clamped within 2 min of delivery and blood $(1 \mathrm{~mL})$ was collected by puncture of the umbilical vein. Blood $(0.5 \mathrm{~mL})$ was sampled at 3-4 d of age and, where possible, two to five more times during the next 4 wk by puncture of a vein on the dorsum of the hand at the time of other clinical sampling (approximately $1000 \mathrm{~h}$ ). Plasma was obtained after centrifugation $\left(3000 \mathrm{rpm}, 15 \mathrm{~min}, 4^{\circ} \mathrm{C}\right)$ and stored at $-70^{\circ} \mathrm{C}$ within $4 \mathrm{~h}$ of collection.

Sterol Analyses. Plasma nonesterified and total cholesterol ( $3 \beta-$ hydroxysterol) levels were determined using enzymatic kits (Diagnostic Chemicals, Ltd.; Charlottetown, Prince Edward Island, Canada). Quality control serum (Sigma Chemical Co., St. Louis, MO) was included in each assay. Sample blanks were assayed if hemolysis was noted. Plasma lathosterol was extracted (21) and quantitated (22) with minor modification. In brief, $5 \alpha$-cholestane, an internal standard (Sigma Chemical Co.), was added to $50-100 \mu \mathrm{L}$ plasma and saponified with $50 \% \mathrm{KOH}$ and methanol $(6: 94, \mathrm{vol} / \mathrm{vol})$ for $1 \mathrm{~h}$ at $80^{\circ} \mathrm{C}$. This was then extracted three times with petroleum ether, dried, and silylated with hexamethyldisilane:trimethylchlorosilane:dimethylformamide, 20:2:5, vol/vol/vol (Pierce; Rockford, IL), $5 \mathrm{~min}$ at room temperature. Recovered sterols were immediately injected into a Varian 3400 gas-liquid chromatograph equipped with flame ionization detection and a Varian 401 data system (Varian Canada Ltd., Georgetown, Ontario, Canada). Separation was achieved on an RTx-1, 25-m capillary column, 0.25-mm internal diameter, $0.25-\mu \mathrm{m}$ thickness (Restek, Corp.; Bellefonte, PA). The column oven was programmed to increase from $80^{\circ} \mathrm{C}$ for $1 \mathrm{~min}$ to $120^{\circ} \mathrm{C}\left(20^{\circ} \mathrm{C} / \mathrm{min}\right)$, hold for $7 \mathrm{~min}$, rise to $249^{\circ} \mathrm{C}\left(20^{\circ} \mathrm{C} / \mathrm{min}\right)$, hold for $15 \mathrm{~min}$, rise to $269^{\circ} \mathrm{C}\left(20^{\circ} \mathrm{C} / \mathrm{min}\right)$, and hold for $20 \mathrm{~min}$. The oven was then heated to $320^{\circ} \mathrm{C}$ before subsequent analyses. The injector and detector were set at 300 and $320^{\circ} \mathrm{C}$, respectively, and the carrier gas (helium) flow was set at $1.25 \mathrm{~mL} / \mathrm{min}$ with an inlet split ratio of $100: 1$ commencing $0.7 \mathrm{~min}$ after the run start. Lathosterol peak identification was confirmed using an authentic standard (Sigma Chemical Co., St. Louis, MO). The interassay coefficient of variation was $11 \%$. Results were calculated as $\mu \mathrm{M}$ lathosterol and the ratio of lathosterol:cholesterol $\left(10^{2} \times \mathrm{mmol}\right.$ lathosterol:mol cholesterol) $(21)$.

Apolipoprotein Analyses. Plasma apo AI and B were measured by immunoprecipitation (Beckman Array Protein System, Palo Alto, CA).

Statistics. Variations among infants in start, dosage, and duration of Intralipid feeding were unavoidable because this study operated within the confines of the best treatment for each patient. Therefore, the only valid statistical comparisons possible were paired $t$ tests between cord and d 3-4 samples because infants' treatments were relatively similar until this point.

Ethics. The study protocols were approved by the clinical screening committees for research and other studies involving human subjects of the University of British Columbia and British
Columbia Children's and Grace Hospitals. Informed consent was obtained from all parents to allow their infant's participation in the lathosterol study.

\section{RESULTS}

Preliminary cholesterol study. Infants were divided into two groups based on whether or not they had received $>2 \mathrm{~g} / \mathrm{kg}$ body wt/d for more than $2 \mathrm{~d}$. Infants in the i.v. lipid group had a lower mean gestational age and birth weight and began enteral feeds later than infants given negligible i.v. lipid (Table 1). Changes in plasma cholesterol versus postnatal age and Intralipid administration of representative infants (Table 2) are plotted in Figures 1 and 2. The clinical profiles of both groups were typical for infants of this degree of immaturity and included hyaline membrane disease, bronchopulmonary dysplasia, septicemia, patent ductus arteriosus, intraventricular hemorrhage, and necrotizing enterocolitis.

Plasma cholesterol levels rose coincident with lipid administration (Fig. 1). The highest level measured for each infant ranged from 4.06 to $10.70 \mathrm{mM}$. In all cases, cholesterol levels decreased after cessation of i.v. lipid infusion. The highest plasma cholesterol levels found for infants receiving negligible Intralipid was $5.17 \mathrm{mM}$ (Fig. 2).

Lathosterol study. These infants were divided into two not mutually exclusive subsets: 1) those for whom paired cord and d 3-4 samples were available $(n=11)$ and 2$)$ those from whom at least three additional samples were collected after d 3-4 of age $(n=10)$. Five infants did not fit either group. Paired cord and $\mathrm{d}$ 3-4 data were not obtained for subjects if the blood had clotted in the cord before sampling, the infant was too sick for investigation, or the blood sample was too small for analysis. Longitudinal sampling was discontinued as a result of extubation (according to concurrent study protocol) or death. The clinical profiles of the participating infants were similar to those in the preliminary study. Serum bilirubin did not exceed $209 \mu \mathrm{M}(12.2$ $\mathrm{mg} / \mathrm{dL}$ ) in any infant.

Cord and $d$ 3-4 subset. The birth weight and gestational age of these infants are shown in Table 3. Two infants were female, two were Oriental, and nine were Caucasian; two were born by cesarean section. The mean plasma cholesterol concentrations of the group of infants studied increased between birth and d 34 , but there was no change in apo AI or B (Table 3). There was, however, considerable variation among individual infants. Thus,

Table 1. Characteristics of infant populations (mean $\pm S D$, range)*

\begin{tabular}{|c|c|c|c|}
\hline & \multicolumn{2}{|c|}{ Preliminary study } & \multirow{2}{*}{$\begin{array}{l}\text { Lathosterol } \\
\text { study } \\
\text { (Longitudinal } \\
\text { i.v. nutrition) }\end{array}$} \\
\hline & $\begin{array}{l}\text { With i.v. } \\
\text { lipid }\end{array}$ & $\begin{array}{l}\text { Without i.v. } \\
\text { lipid }\end{array}$ & \\
\hline$n$ & 12 & 9 & 10 \\
\hline Birth weight (g) & $\begin{array}{r}954 \pm 343 \\
(655-1800)\end{array}$ & $\begin{array}{l}1227 \pm 170 \\
(955-1475)\end{array}$ & $\begin{array}{l}1030 \pm 172 \\
(665-1225)\end{array}$ \\
\hline Gestational age (wk) & $\begin{array}{l}26.0 \pm 2.2 \\
(24-31)\end{array}$ & $\begin{array}{l}28.9 \pm 1.3 \\
(28-31)\end{array}$ & $\begin{array}{l}26.6 \pm 1.6 \\
(23-29)\end{array}$ \\
\hline $\begin{array}{l}\text { Onset of Intralipid } \\
\text { infusion (d) }\end{array}$ & $\begin{array}{l}6.5 \pm 2.6 \\
(3-12)\end{array}$ & & $\begin{array}{l}3.9 \pm 1.3 \\
(3-7)\end{array}$ \\
\hline $\begin{array}{l}\text { Onset of enteral feeds } \\
\text { (d) }\end{array}$ & $\begin{array}{l}14.3 \pm 8.4 \\
(1-33)\end{array}$ & $\begin{array}{c}3.1 \pm 1.6(n=7) \dagger \\
(1-5)\end{array}$ & $\begin{array}{l}6.2 \pm 3.2 \\
(3-12)\end{array}$ \\
\hline $\begin{array}{l}\mathrm{EBM} / \text { formula/mix } \\
\qquad(\%)\end{array}$ & $42 / 42 / 16$ & $38 / 12 / 50$ & $40 / 20 / 40$ \\
\hline $\operatorname{Sex}(F / M)$ & $5 / 7$ & $3 / 6$ & $4 / 6$ \\
\hline Delivery (SVD/CS) & $8 / 4$ & $5 / 4$ & $5 / 5$ \\
\hline Race $(\mathrm{C} / \mathrm{O} / \mathrm{EI})$ & $10 / 0 / 2$ & $8 / 0 / 1$ & $8 / 2 / 0$ \\
\hline
\end{tabular}

*EBM, expressed breast milk; SVD/CS, spontaneous vaginal delivery/cesarean section; C/O/EI, Caucasian/Oriental/East Indian.

$\dagger$ Only eight of nine infants received enteral feeds during the study,

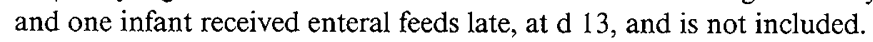


Table 2. Details of infants presented in Figures 1-4

\begin{tabular}{|c|c|c|c|c|c|c|c|}
\hline Infant & Sex & $\begin{array}{l}\text { Birth } \\
\text { weight } \\
\text { (g) }\end{array}$ & $\begin{array}{l}\text { Gestational } \\
\text { age (wk) }\end{array}$ & Delivery & $\begin{array}{l}\text { Onset of } \\
\text { amino acid } \\
\text { infusion } \\
\text { (d) }\end{array}$ & Enteral feeds & Clinical features \\
\hline A & M & 1800 & 31 & SVD & 6 & $\begin{array}{l}\text { EBM d 16-22, Pregestimil d 23- } \\
\quad 38 \text {, d 46- }\end{array}$ & $\begin{array}{l}\text { HMD, BPD, NEC, gastroin- } \\
\text { testinal surgery d } 6,38\end{array}$ \\
\hline B & $\mathrm{M}$ & 980 & 25 & SVD & 3 & SCF 68 d $15-22$, SCF 81 d 22- & Severe IVH \\
\hline $\mathrm{C}$ & $\mathrm{F}$ & 700 & 24 & SVD & 2 & EBM d 33-57, Prosoybee d 57- & HMD, BPD, NEC, IVH \\
\hline $\mathrm{D}$ & $\mathbf{M}$ & 720 & 25 & SVD & 2 & $\begin{array}{l}\text { EBM d 8-14, d 24-63, SCF } 81 \text { d } \\
\quad 62-70, \text { EBM d } 71-\end{array}$ & HMD, BPD, PIE \\
\hline $\mathrm{E}$ & $\mathrm{F}$ & 1000 & 28 & $\mathrm{CS}$ & 2 & $\begin{array}{l}\text { EBM d 6-36, SCF } 81 \text { d 36-46, } \\
\text { EBM/SCF } 81 \text { d 46- }\end{array}$ & HMD, BPD, twin \\
\hline $\mathrm{F}$ & M & 955 & 28 & CS & 2 & SCF 68 d $13-34$, SCF 81 d $34-$ & $\mathrm{HMD}, \mathrm{BPD}, \mathrm{NEC}$ \\
\hline G & $\mathrm{F}$ & 1130 & 28 & SVD & 3 & EBM/SCF $68 \mathrm{~d} 12-$ & $\begin{array}{l}\text { Birth asphyxia, HMD, PIE, } \\
\text { pneumonia, IVH, PDA }\end{array}$ \\
\hline $\mathrm{H}$ & $\mathbf{M}$ & 1080 & 28 & $\mathrm{CS}$ & 3 & EBM/SCF 68 d 11-12, d 19- & HMD, BPD, NEC, PDA \\
\hline I & $\mathrm{F}$ & 925 & 26 & $\mathrm{CS}$ & 2 & EBM/SCF 68 d 2-5, EBM d 5- & HMD, septicemia, PDA \\
\hline $\mathbf{J}$ & M & 685 & 23 & SVD & 3 & SCF 68 d 5-8 & $\begin{array}{l}\text { Birth asphyxia, HMD, NEC, } \\
\text { PDA, spastic quadriplegia }\end{array}$ \\
\hline $\mathrm{K}$ & M & 875 & 26 & SVD & 3 & EBM d $8-14$, d $18-$ & $\begin{array}{l}\text { HMD, BPD, PDA, respiratory } \\
\text { infection d } 16\end{array}$ \\
\hline $\mathrm{L}$ & $\mathbf{M}$ & 1140 & 26 & SVD & 3 & EBM d 14- & $\begin{array}{l}\text { Septicemia, PDA, inguinal } \\
\text { hernia surgery } d 8\end{array}$ \\
\hline M & M & 920 & 26 & SVD & 2 & EBM d 5- & $\begin{array}{l}\text { HMD, pneumonia, IVH, sep- } \\
\text { ticemia }\end{array}$ \\
\hline $\mathrm{N}$ & $\mathrm{M}$ & 1025 & 27 & CS & 3 & EBM/SCF 68 d 4 & $\begin{array}{l}\text { Perinatal asphyxia, HMD, } \\
\text { BPD, PDA }\end{array}$ \\
\hline
\end{tabular}

SVD, spontaneous vaginal delivery; CS, cesarean section; HMD, hyaline membrane disease; BPD, bronchopulmonary dysplasia; PDA, patent ductus arteriosus; IVH, intraventricular hemorrhage; PIE, pulmonary interstitial emphysema; NEC, necrotizing enterocolitis; EBM, expressed breast milk; and SCF, Special Care formula.

the plasma cholesterol decreased in three of 11 infants, showed no change in one of 11 infants, and increased in eight of 11 infants over the first 3-4 d of life (Table 3). The plasma lathosterol concentration and the ratio of lathosterol:cholesterol, however, decreased. There were no differences in any of these parameters between infants whose mothers were $(n=4)$ or were not given dexamethasone before delivery. The administration of small amounts of Intralipid ( $<1 \mathrm{~g} / \mathrm{kg}$ body wt $/ \mathrm{d}, n=2)$ before the d 3-4 sampling did not have any discernible effect.

Longitudinal subset. Characteristics of the infants studied are shown in Table 1. Three infants were Oriental and the remainder were Caucasian. Cholesterol, apo AI and B, and lathosterol concentrations and i.v. lipid intake for representative infants (Table 2) are plotted in Figures 3 and 4.

The rise in plasma lathosterol was coincident with the infusion of Intralipid and increase in plasma cholesterol. In the three infants for whom Intralipid was stopped before the final sample was taken, plasma sterol concentrations returned to preinfusion levels (e.g. Fig. 3, infant L). Apo AI and B levels either did not change or decreased during Intralipid infusion. In the two infants who received negligible Intralipid (Fig. 4), plasma lathosterol levels increased slightly after birth, but showed no further increase over the $11 \mathrm{~d}$ studied. Plasma apo AI increased in one of these infants (M), but cholesterol and apo B did not change appreciatively in either.

\section{DISCUSSION}

Cord plasma analyses. The cord plasma cholesterol, apo AI, and apo B concentrations found here are similar to published levels for infants of similar gestational age (3, 23-29). The higher cord plasma cholesterol levels in very preterm than in term infants $(25,26,28)$ have been hypothesized to reflect enhanced hepatic cholesterol synthesis related to a spurt in liver growth (14). Our finding that cord lathosterol concentrations are not different in preterm than term (unpublished observation) infants does not support this hypothesis.
Lathosterol concentrations were much more variable among preterm (Table 3 ) than among term infants (unpublished observation). This may reflect collection of cord plasma from only elective cesarean section births in the term but not the preterm infants, inasmuch as the many variables of labor and delivery that affect cord plasma cholesterol levels (30) might also influence cholesterol synthesis rates. One such variable is maternal dexamethasone administration, which is often given before preterm delivery to reduce neonatal respiratory distress (31). This results in increased total, HDL, and LDL cholesterol and apo AI levels in 26-32 wk gestation infants and has been suggested to be related to enhanced fetal cholesterol synthesis (32). Four infants in our study were exposed to dexamethasone at a wide range of times before birth. Possibly, this contributed to the high degree of variability in the preterm cord lathosterol results.

Cord versus $d$ 3-4. Preterm plasma cholesterol concentrations increased about $20 \%$ over the first 3-4 d of life, whereas lathosterol concentrations decreased by about $45 \%$. In term infants sampled at comparable ages, cholesterol increased $40 \%$ and lathosterol decreased $10 \%$ (unpublished observation). It seems that, irrespective of gestational age, cholesterol synthesis does not increase in the early newborn period. Preterm infants are often in negative energy balance at 3-4 d of age when supported by parenteral nutrition without lipid. Their apparently larger decrease in cholesterol synthesis might be explained by limiting acetyl CoA levels for biosynthetic pathways.

Infants not receiving Intralipid. In agreement with reports for enterally fed preterm infants $(23,28)$, hypercholesterolemia did not occur in infants given negligible Intralipid. Of further note, lathosterol levels did not increase. The results, however, indicate that enterally fed preterm infants may not experience the increase in plasma cholesterol levels that are typical of term infants and believed to be associated with the onset of oral feeding (1).

Apoprotein analysis of the two infants who received negligible Intralipid showed no notable changes in apo B containing LDL and VLDL. HDL (as indicated by apo AI) levels increased in infant $\mathrm{M}$, but no changes were seen in infant $\mathrm{N}$. Others have 

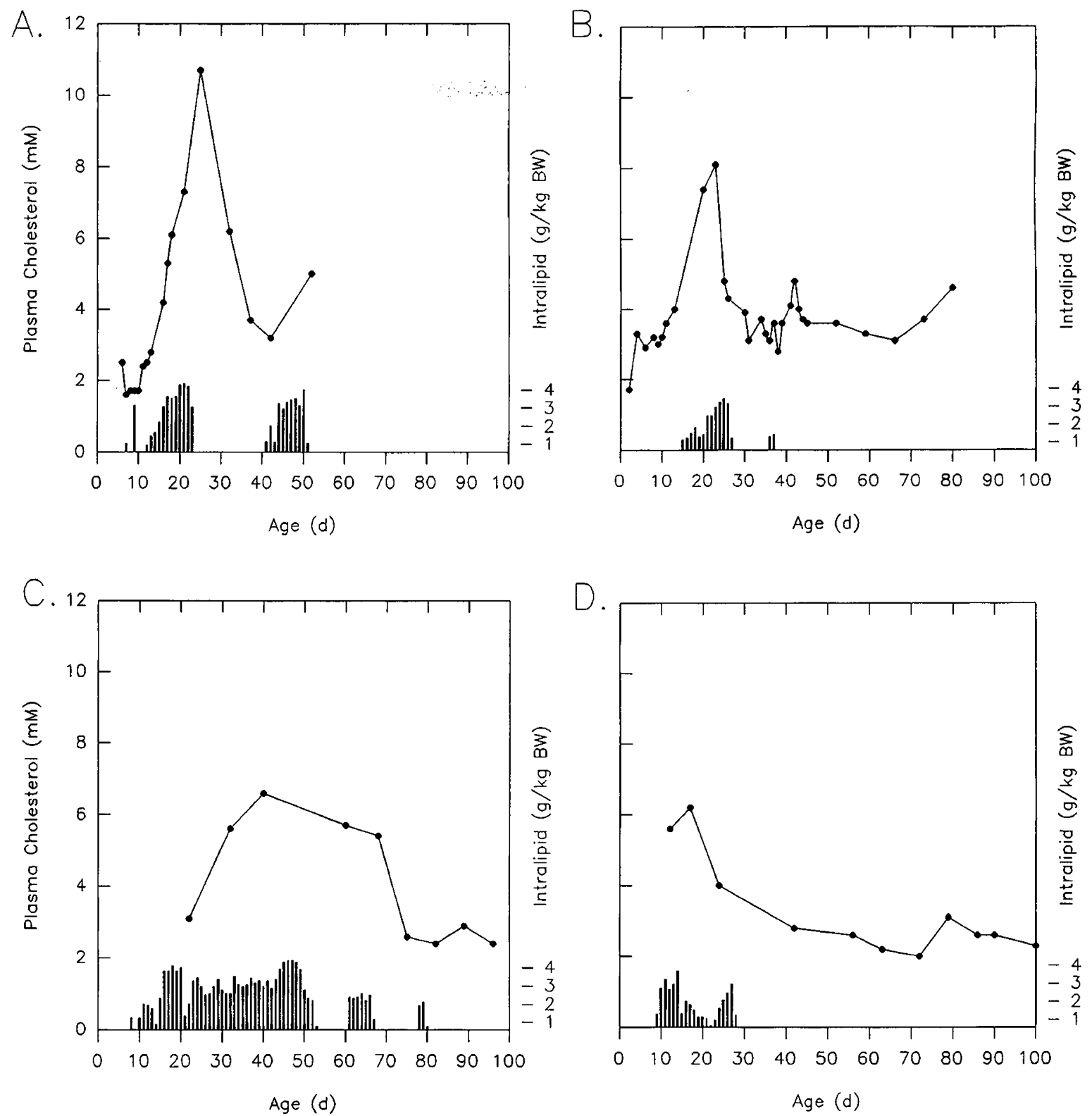

Fig. 1. Plasma cholesterol levels (•) and Intralipid infusion rates (solid bars) over the first $100 \mathrm{~d}$ of life of four representative preterm infants. Infants are described in Table 2.

reported at least a transient increase in apo AI (28), HDL cholesterol $(23,27,33)$, or VLDL or LDL cholesterol $(23,27)$ in preterm infants given only enteral nutrition in the 1st mo of life.

Infants receiving Intralipid. Intralipid, an emulsion of soybean oil triglyceride and egg yolk phospholipid, is often administered for prolonged periods to infants unable to tolerate adequate enteral nutrition. Its metabolism involves association of the emulsion particles with $\mathrm{C}$ apoproteins and triglyceride hydrolysis via lipoprotein lipase $(17,34)$. The resulting phospholipid-rich vesicles, after inclusion of more $\mathrm{C}$ apoproteins, albumin, and equimolar amounts of nonesterified cholesterol, are commonly referred to as LpX particles. Plasma cholesterol levels increase cumulatively when Intralipid is infused $(7-10,12)$. Griffin et al. (2) calculated that, although Intralipid contains about $4 \mathrm{mg}$ cholesterol and $2 \mathrm{mg}$ plant sterols/g triglyceride, at least $50 \%$ of the excess plasma cholesterol is derived from endogenous sources. Plant sterols were only slightly elevated in infants given Intralipid for either $24 \mathrm{~h}$ or $2.5 \mathrm{mo}$ (2). It seems unlikely, therefore, that the elevation of plasma cholesterol in our study is explained by accumulation of infused plant sterol, which was not discriminated by the plasma cholesterol ( $3 \beta$-hydroxysterol) enzymatic assay used.
Presumptive evidence for accumulation of $\mathrm{LpX}$ in this study includes 1) elevated plasma nonesterified cholesterol levels (data not shown) in infants during Intralipid administration but not in those given negligible Intralipid or fed enterally. (27) and 2) the failure of apo AI or B to increase during Intralipid infusion (Fig. 3). A decrease in apo AI, with higher AI levels when enteral feeds were introduced, has been reported by others (5). It has been hypothesized that decreased HDL cholesterol levels in adults given parenteral nutrition may be due to the lack of nutritional input at the intestine, a site of apo AI synthesis (35). We found no evidence of increased apo AI with enteral feeding. The reduced apo B levels during Intralipid administration (Fig. 3) could be the result of perturbation of hepatic triglyceride synthesis and secretion of VLDL as hypothesized for adults (35).

The increase in plasma lathosterol levels in concert with Intralipid administration, together with the fall in lathosterol levels upon cessation of lipid infusion, provides the first evidence of increased cholesterol synthesis associated with Intralipid infusion. Lathosterol levels rose to values 4 - to 7 -fold higher than reported for normal term infants (cord or d 4) or adults, into the range of hypercholesterolemic adults treated with cholestyr- 

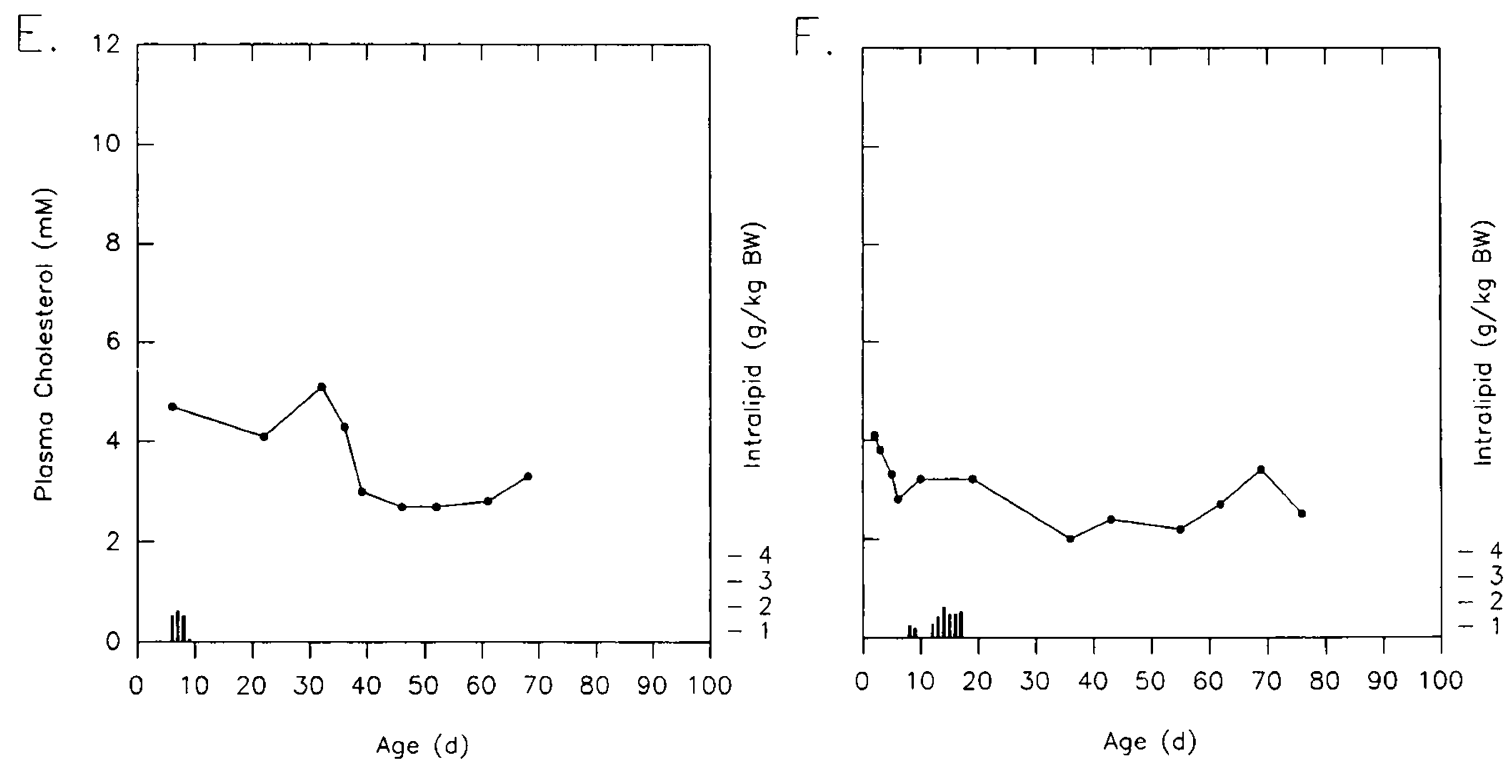

Fig. 2. Plasma cholesterol levels ( $)$ and Intralipid infusion rates (solid bars) over the first $100 \mathrm{~d}$ of life of two representative preterm infants administered negligible Intralipid, which is defined as $>2 \mathrm{~g} / \mathrm{kg}$ body wt/d for more than $2 \mathrm{~d}$. Infants are described in Table 2 .

Table 3. Levels of cholesterol, apo AI and B, and lathosterol in plasma of preterm infants at birth (cord) and 3-4 d of life*

\begin{tabular}{|c|c|c|c|c|c|c|c|c|c|c|c|c|}
\hline \multirow[b]{2}{*}{ Infant } & \multirow{2}{*}{$\begin{array}{l}\text { Birth } \\
\text { weight } \\
(\mathrm{g})\end{array}$} & \multirow{2}{*}{$\begin{array}{c}\text { Gestational } \\
\text { age (wk) }\end{array}$} & \multicolumn{2}{|c|}{$\begin{array}{l}\text { Cholesterol } \\
\text { (mM) }\end{array}$} & \multicolumn{2}{|c|}{ Apo AI (g/L) } & \multicolumn{2}{|c|}{ Apo B $(g / L)$} & \multicolumn{2}{|c|}{$\begin{array}{l}\text { Lathosterol } \\
\qquad(\mu \mathrm{M})\end{array}$} & \multicolumn{2}{|c|}{$\begin{array}{c}\text { Lathosterol } \\
\left(10^{2} \times \mathrm{mmol}\right): \\
\text { cholesterol } \\
(\mathrm{mol})\end{array}$} \\
\hline & & & Cord & d $3-4$ & Cord & d 3-4 & Cord & d 3-4 & Cord & d $3-4$ & Cord & d 3-4 \\
\hline SW & 920 & 26 & 1.32 & 2.53 & 0.35 & 0.48 & 0.22 & 0.39 & 3.03 & 2.48 & 229 & 98 \\
\hline $\mathrm{AB}$ & 975 & 28 & 2.12 & 1.76 & 0.52 & 0.44 & 0.20 & 0.20 & 8.90 & 1.21 & 419 & 69 \\
\hline $\mathrm{NC}$ & 1066 & 27 & 1.34 & 2.74 & 0.22 & 0.33 & 0.28 & 0.34 & 2.48 & 3.28 & 185 & 120 \\
\hline NP & 685 & 23 & 1.60 & 1.37 & 0.50 & 0.40 & & 0.14 & 7.16 & 2.07 & 446 & 151 \\
\hline $\mathrm{JM}$ & 1195 & 29 & 1.66 & 1.60 & 0.50 & 0.43 & 0.16 & & 4.97 & 3.05 & 300 & 190 \\
\hline SK & 1130 & 28 & 1.29 & 2.43 & 0.61 & 0.53 & 0.09 & 0.31 & 1.84 & 2.01 & 142 & 83 \\
\hline $\mathrm{JRa}$ & 1480 & 32 & 2.15 & 2.51 & 0.36 & 0.67 & 0.17 & 0.37 & 4.34 & 1.84 & 202 & 74 \\
\hline $\mathrm{JRb}$ & 1700 & 32 & 3.39 & 2.53 & 0.89 & 0.76 & 0.36 & 0.20 & 4.68 & 1.73 & 138 & 69 \\
\hline MR & 1025 & 27 & 1.76 & 2.02 & 0.56 & 0.38 & & & 2.84 & 2.30 & 162 & 114 \\
\hline EL & 875 & 26 & 1.19 & 1.50 & 0.54 & 0.56 & 0.10 & 0.15 & 5.17 & 2.04 & 435 & 136 \\
\hline SJ & 1050 & 26 & 2.64 & 3.67 & 0.48 & 0.49 & 0.35 & 0.12 & 12.23 & 9.70 & 464 & 264 \\
\hline Mean & 1100 & 27.6 & 1.86 & 2.24 & 0.50 & 0.50 & 0.21 & 0.25 & 5.24 & 2.88 & 284 & 124 \\
\hline $\mathrm{SD}$ & 282 & 2.7 & 0.67 & 0.68 & 0.17 & 0.13 & 0.10 & 0.11 & 3.11 & 2.33 & 133 & 60 \\
\hline$n$ & 11 & 11 & 11 & 11 & 11 & 11 & 9 & 9 & 11 & 11 & 11 & 11 \\
\hline$p^{\dagger}$ & & & \multicolumn{2}{|c|}{0.06} & \multicolumn{2}{|c|}{0.5} & \multicolumn{2}{|c|}{0.5} & \multicolumn{2}{|c|}{0.01} & \multicolumn{2}{|c|}{0.007} \\
\hline
\end{tabular}

* Missing values indicate insufficient sample volume for analysis.

$\dagger$ Paired two-tailed $t$ tests were performed in all cases except for plasma cholesterol, where a one-tailed test was used.

amine resin (unpublished observations). Increased cholesterol synthesis, measured by hepatic HMG CoA reductase activity, has also been reported in rats given lecithin mesophase infusion (36). However, a similarly induced hypercholesterolemia occurred even in the absence of a functioning liver (37), suggesting that the increased cholesterol synthesis may be extrahepatic. In this regard, Innis and Boyd (38) found that rats infused with Intralipid had increased adipose tissue and skeletal muscle, but decreased hepatic, HMG CoA reductase activity. It thus seems possible that the increased lathosterol levels in the i.v. lipidinfused preterm infant could reflect extrahepatic cholesterol synthesis. This hypothesis is compatible with decreasing apo AI and B levels because the transfer of extrahepatic membrane cholesterol to the plasma would not depend on the secretion of lipoproteins.

Summary. It appears that $10 \%$ Intralipid administered to preterm infants (23-32 wk gestation) is accompanied by increased cholesterol synthesis (as measured by plasma lathosterol concentrations), which may be of extrahepatic origin. Several potential complications of i.v. lipid administration to preterm infants have been proposed $(39,40)$, but the impact of changes in cholesterol synthesis is unknown. Studies in other species have suggested long-term effects on cholesterol homeostasis (41). The potential effect of increased use of two-carbon units for sterol synthesis to other metabolic pathways may also be worth consideration.

Recent studies have shown that i.v. lipid solutions that contain $20 \%$ lipid ( $50 \%$ less phospholipid/kJ) or mixtures of mediumchain and long-chain triglycerides minimize or do not elicit hypercholesterolemia in infants $(12,13,42)$ or adults (34). The lathosterol methodology described may be of value in defining the effect of these solutions on tissue cholesterol synthesis.

Acknowledgments. The authors thank Murray MacKinnon, of the Research Support Unit of the British Columbia Children's Hospital, for statistical assistance; Dr. Wadsworth for providing access to laboratory samples; and Justine Stewart, Marie Yeo, 

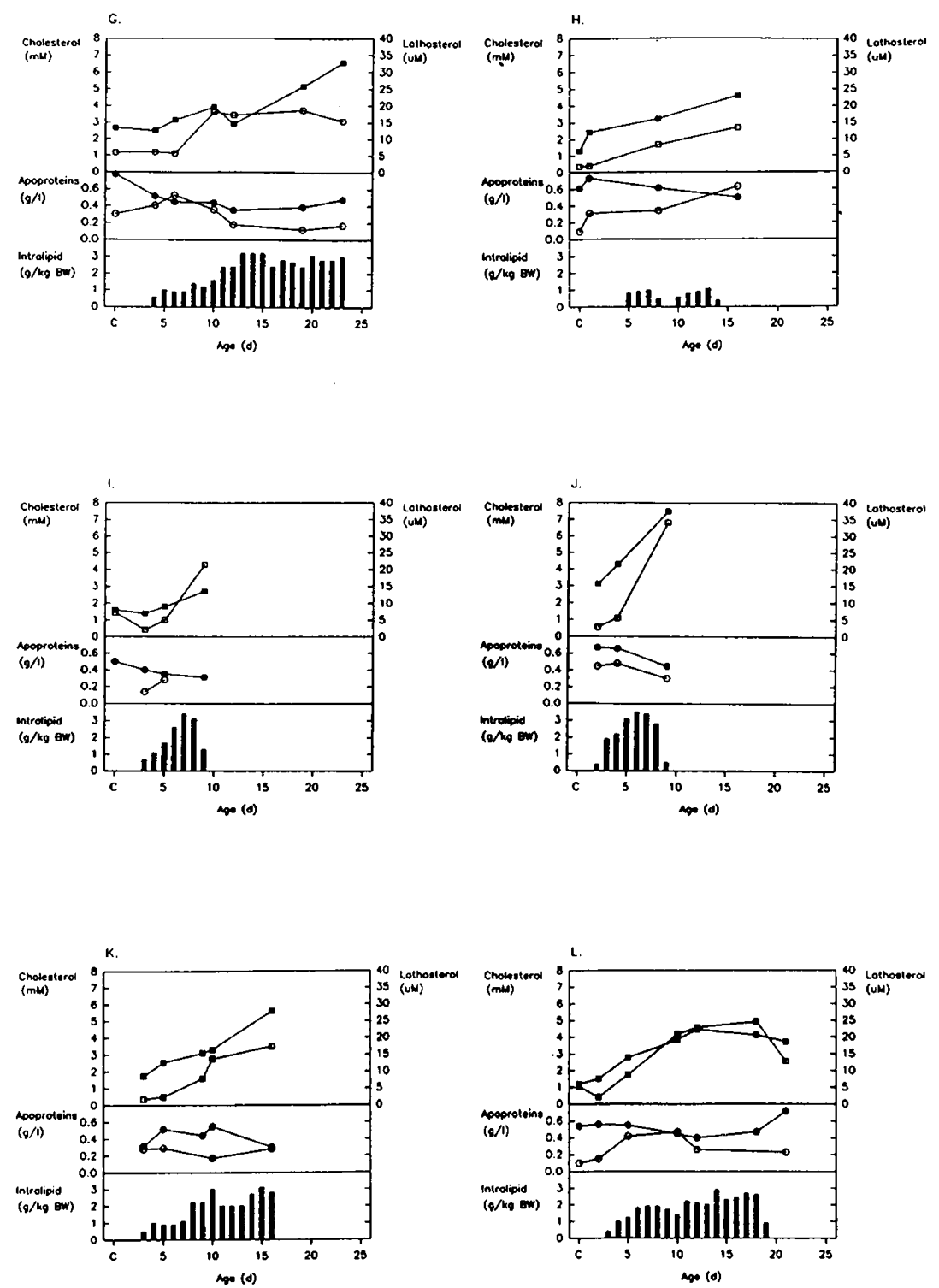

Fig. 3. Plasma cholesterol (ם), lathosterol $(\square)$, and apolipoprotein $\mathrm{AI}(\bullet)$ and B $(\mathrm{O})$ levels and Intralipid infusion rats (solid bars) over the first $25 \mathrm{~d}$ of life of six representative preterm infants. All available data is plotted. Infants are described in Table 2.
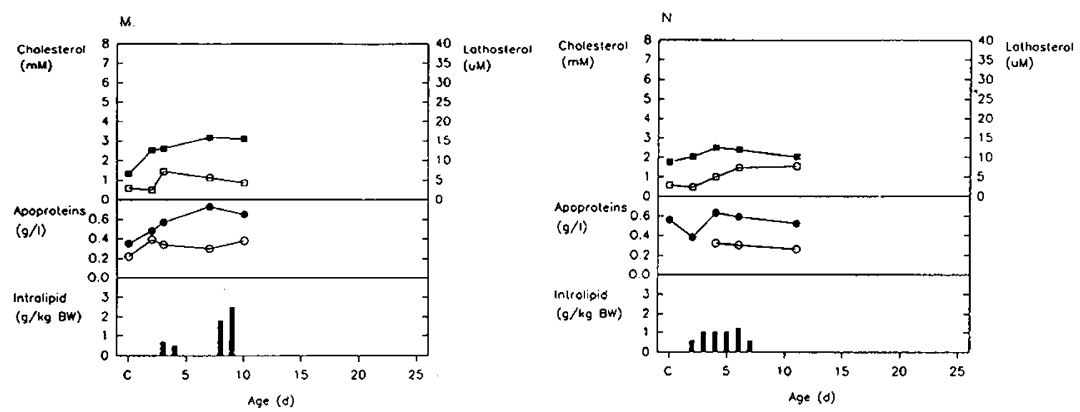

Fig. 4. Plasma cholesterol $(\square)$, lathosterol $(\square)$, and apolipoprotein AI $(\bullet)$ and B $(O)$ levels and Intralipid infusion rates (solid bars) over the first $13 \mathrm{~d}$ of life of two representative preterm infants administered negligible Intralipid, which is defined as $>2 \mathrm{~g} / \mathrm{kg}$ body wt/d for more than $2 \mathrm{~d}$. All available data is plotted. Infants are described in Table 2.

and Dr. J. Smyth for assisting in infant recruitment, sample collection, and processing.

\section{REFERENCES}

1. Potter J 1977 Perinatal plasma lipid concentrations. Aust N Z J Med 7:155160

2. Griffin E, Breckenridge WC, Kuksis A, Bryan MH, Angel A 1979 Appearance and characterization of lipoprotein $\mathrm{X}$ during continuous Intralipid infusions in the neonate. J Clin Invest 64:1703-1712

3. Higgs SC, Malan AF, Heese HDV 1974 A comparison of oral feeding and total parenteral nutrition in infants of very low birthweight. S Afr Med J 48:21692173

4. Rovamo L 1985 Post-heparin plasma lipases and carnitine in infants during parenteral nutrition. Pediatr Res 19:292-296

5. Bargen-Lockner C, Hahn P, Pendray M, Riddell G 1983 Effect of Intralipid on total and high-density lipoprotein cholesterol levels in newborns and infants. Biol Neonate 44:272-277 
6. Franklin FA, Watkins JB, Heafitz L, Clowes AW, Breslow JL 1976 Serum lipids during total parenteral nutrition with Intralipid. Pediatr Res 10:354(abstr)

7. Kao LC, Cheng MH, Warburton D 1984 Triglycerides, free fatty acids, free fatty acids/albumin molar ratio, and cholesterol levels in serum of neonates receiving long-term lipid infusions: controlled trial of continuous and intermittent regimes. J Pediatr 104:429-435

8. Cooke RJ, Yeh YY, Gibson D, Debo D, Bell GL 1987 Soybean oil emulsion administration during parenteral nutrition in the preterm infant: effect on essential fatty acid, lipid and glucose metabolism. J Pediatr 111:767-773

9. Berkow SE, Spear ML, Stahl GE, Gutman A, Polin RA, Pereira GR, Olivecrona T, Hamosh P, Hamosh M 1987 Total parenteral nutrition with Intralipid in premature infants receiving TPN with heparin: effect on plasma lipolytic enzymes, lipids, and glucose. J Pediatr Gastroenterol Nutr 6:581-588

10. Brans YW, Andrew DS, Carrillo DW, Dutton EP, Menchaca EM, PuleoScheppke BA 1988 Tolerance of fat emulsions in very-low-birth-weight neonates. Am J Dis Child 142:145-152

11. Brans YW, Andrew DS, Carrillo DW, Dutton EP, Menchaca EM, PuleoScheppke BA 1990 Tolerance of fat emulsions in very low birthweight neonates: effect of birth weight on plasma lipid concentrations. Am J Perinatol 7:114-117

12. Lima LAM, Murphy JF, Stansbie D, Rowlandson P, Gray OP 1988 Neonatal parenteral nutrition with a fat emulsion containing medium chain triglycerides. Acta Paediatr Scand 77:332-339

13. Haumont D, Deckelbaum RJ, Richelle M, Dahlan W, Coussaert E, Bihain BE, Carpentier YA 1988 Plasma lipid and plasma lipoprotein concentrations in low birth weight infants given parenteral nutrition with twenty or ten percent lipid emulsion. J Pediatr 115:787-793

14. Johnson HJ, Simpson ER, Carr BR, MacDonald PC, Parker CR 1982 The levels of plasma cholesterol in the human fetus throughout gestation. Pediatr Res 16:682-683

15. Dahms BB, Halpin TC 1980 Pulmonary arterial lipid deposit in newborn infants receiving intravenous lipid infusion. J Pediatr 97:800-805

16. Thompson GR, Segura R, Hoff H, Gotto AM 1975 Contrasting effects on plasma lipoproteins of intravenous versus oral administration of a triglyceride-phospholipid emulsion. Eur J Clin Invest 5:373-384

17. Untracht SH 1982 Intravascular metabolism of an artificial transporter of triacylglycerols; alterations of serum lipoproteins resulting from total parenteral nutrition with intralipid. Biochim Biophys Acta 711:176-192

18. Kandutsch A, Taylor F 1985 Control of de novo cholesterol synthesis. In: Strauss J, Meon K (eds) Lipoprotein and Cholesterol Metabolism in Steroidogenic Tissues. George F. Stickley Co., Philadelphia, PA, pp 1-7

19. Parker TS, McNamara DJ, Brown CD, Kolb R, Ahrens EH, Alberts AW, Tobert J, Chen J, De Schepper PJ 1984 Plasma mevalonate as a measure of cholesterol synthesis in man. J Clin Invest 74:795-804

20. Jones PJH, Schoeller DA 1990 Evidence for diurnal periodicity in human cholesterol synthesis. J Lipid Res 31:667-674

21. Farkkila MA, Miettinen TA 1988 Plasma lathosterol and campesterol in detection in ileal dysfunction. Scand J Gastroenterol 23:19-25

22. Bjorkhem I, Miettinen T, Reihner E, Ewerth S, Angelin B, Einarsson K 1987 Correlation between serum levels of some cholesterol precursors and activity of HMG-CoA reductase in human liver. J Lipid Res 28:1137-1143

23. Decsi T, Molnar D, Klujber L 1990 Lipid levels in very low birthweight preterm infants. Acta Paediatr Scand 79:577-580
24. Lane DM, McConathy WJ 1983 Factors affecting the lipid and apoprotein levels of cord sera. Pediatr Res 17:83-91

25. Amr S, Chowdry P, Hamosh P, Hamosh M 1988 Low levels of apolipoprotein $\mathrm{Al}$ are not contributors to the low lecithin-cholesterol acyl transferase activity in premature newborn infants. Pediatr Res 24:191-193

26. Sharma SC, Misra PK, Tolani MK, Kaul R 1983 Lipid profile in the early neonatal period in normal and low birth weight infants. Indian Pediat 20:179-183

27. Ginzberg BE, Zetterstrom R 1980 Serum cholesterol concentrations in newborn infants with gestational ages of 28-42 weeks. Acta Paediatr Scand 69:587-592

28. Genzel-Boroviczeny O, D'Harlingue AE, Kao LC, Scott C, Forte TM 1988 High-density lipoprotein subclass distribution in premature newborns before and after onset of enteral feeding. Pediatr Res 23:543-547

29. Parker CR, Fortunato SJ, Carr BR, Owen J, Hankins GDV, Hauth JC 1988 Apoprotein A-1 in umbilical cord blood of newborn infants: relation to gestational age and high-density lipoprotein cholesterol. Pediatr Res 23:348351

30. Boulton TJC 1979 Fetal, maternal and intrapartum factors and their effects on cord serum cholesterol and triglycerides. Aust N Z J Med 9:57-62

31. Liggins GC, Howie RN 1972 A controlled trial of antepartum glucocorticoid treatment for prevention of the respiratory distress syndrome in premature infants. Pediatrics 50:515-525

32. Parker CR, MacDonald PC, Carr BR, Morrison JC 1987 The effects of dexamethasone and anencephaly on newborn serum levels of apoprotein AI. J Clin Endocrinol Metab 65:1098-1101

33. Ginzberg BE, Zetterstrom R 1977 High density lipoprotein concentrations in newborn infants. Acta Paediatr Scand 66:39-41

34. Messing B, Peynet J, Poupon J, Pfeiffer A, Thuillier F, Chazouilleres O, Legrand A 1990 Effect of fat-emulsion phospholipids on serum lipoprotein profile during $1 \mathrm{mo}$ cyclic total parenteral nutrition. Am $\mathbf{J}$ Clin Nut 52:1094-1100

35. Weinberg RB, Singh KK 1989 Short-term parenteral nutrition with glucose and Intralipid effects on serum lipids and lipoproteins. Am J Clin Nutr 49:794-798

36. Jakoi L, Quarfordt SH 1974 The induction of hepatic cholesterol synthesis in the rat by lecithin mesophase infusions. J Biol Chem 249:5840-5844

37. Edwards PA 1975 Effect of plasma lipoproteins and lecithin-cholesterol dispersions on the activity of 3-hydroxy-3-methylglutaryl-coenzyme A reductase of isolated rat hepatocytes. Biochim Biophys Acta 409:39-50

38. Innis SM, Boyd MC 1983 Cholesterol and bile acid synthesis during total parenteral nutrition with and without lipid emulsion in the rat. Am J Clin Nutr 38:95-100

39. Friedman Z, Marks KH, Maisels J, Thorson R, Naeye R 1978 Effect of parenteral fat emulsion on the pulmonary and reticuloendothelial systems in the newborn infant. Pediatrics 61:694-698

40. Stahl GE, Spear ML, Hamosh M 1986 Intravenous administration of lipid emulsions to premature infants. Clin Perinatol 13:133-162

41. Innis SM, Hamilton JJ 1991 Cholesterol metabolism in infancy: changes with development and effect of early nutrition. Proceedings of the IUNS/WHO workshop: Nutrition in the Pediatric Age Group and Later Cardiovascular Disease. Baden/Wein, Austria, September 17-18, 1990

42. Wells DH, Ferlauto JJ, Forbes DJ, Graham TR, Newell RW, Wareham JA, Wilson CA 1989 Lipid tolerance in the very low birth weight infant on intravenous and enteral feedings. JPEN J Parenter Enteral Nutr 13:623-627 